\title{
Legislação ambiental da Paraíba: contribuições à gestão integrada de resíduos sólidos
}

\author{
: Environmental Legislation of State of Paraíba: contributions to Management Integrated of Solid Waste \\ Hérika Juliana Linhares Maia ${ }^{1}$, Janierk Pereira de Freitas ${ }^{2}$, Layana Dantas de Alencar ${ }^{3}$, \\ Lívia Poliana Santana Cavalcante ${ }^{4}$, Erivaldo Moreira Barbosa ${ }^{5}$ \\ 1,2,3,4 Doutoranda(s) em Recursos Naturais, Programa de Pós-graduação em Recursos Naturais - PPGRN, Universidade Federal Campina \\ Grande - UFCG, Campina Grande, PB, Brasil \\ ${ }^{5}$ Pós-doutor em Educação, Professor do Departamento de Ciências Jurídicas e Sociais - CCJS, Universidade Federal de Campina Grande \\ UFCG, Campina Grande, PB, Brasil
}

\begin{abstract}
Resumo
Os impactos do manejo inadequado dos resíduos sólidos repercutem negativamente no ambiente e na saúde da sociedade. A legislação corresponde a um dos instrumentos da gestão ambiental, uma vez que o Direito é uma ciência que regula os acontecimentos sociais, dentre estes, os problemas ambientais. A pesquisa documental foi realizada a partir da análise de documentos com valor científico, da observância da Lei 12.305/10, a qual instituiu a Política Nacional de Resíduos Sólidos-PNRS, bem como da legislação voltada a problemática dos resíduos sólidos no Estado da Paraíba. Os resultados mostraram que as diretrizes trazidas pela Lei 12.305/10 refletiram nas normas estaduais paraibanas, uma vez que as mesmas passaram a tratar de temas relacionados à gestão dos resíduos sólidos, tais como: realização da coleta seletiva nas escolas estaduais; incentivo à organização dos catadores de materiais recicláveis e utilização de sacolas biodegradáveis. Contudo, os avanços legislativos ainda mostram-se tímidos e distantes de modificar a realidade de fato, pois a materialização do Direito não depende apenas da edição dos textos normativos, mas também da participação popular e da vontade política.
\end{abstract}

Palavras-chaves: Legislação Ambiental. Resíduos Sólidos. Gestão Ambiental.

\begin{abstract}
The impacts of inadequate solid waste management have a negative effect on the environment and health of society. The legislation corresponds to one of the instruments of environmental management, since the law is a science that regulates the social events, among them, the environmental problems. The documentary research was carried out through analysis with scientific value, the observance of the Law 12.305/10, which established the National Solid Waste Policy-PNRS and the issue of solid waste in the state of Paraíba focused legislation. The results showed that the guidelines introduced by Law 12.305/10 reflected in the Paraíba state standards, since they started to address issues related to solid waste management, such as realization of selective collection in state schools; encouraging the organization of waste pickers and use of biodegradable bags. However, legislative developments still show up shy and distant to change the reality of fact, for the materialization of law depends not only on the issue of legal texts, but also popular participation and political will.
\end{abstract}

Keywords: Environmental legislation. Solid Waste. Environmental Management. 


\section{INTRODUÇÃO}

O processo de urbanização e expansão das cidades devido ao crescimento populacional, atrelado ao desenvolvimento tecnológico que otimiza cada vez mais o consumismo, tem gerado um dos principais problemas da atualidade: o aumento da geração de resíduos sólidos e a dificuldade de regulamentação de seu destino. Cada sociedade possui um padrão de consumo relacionado aos seus hábitos culturais que geram mais ou menos resíduos sólidos. A falta de direcionamento adequado dos mesmos provoca impactos de ordem econômica, social e ambiental, acarretando em consequências que interferem diretamente na qualidade de vida das pessoas.

O correto manejo dos resíduos sólidos configura-se em um dos maiores desafios da sociedade contemporânea, uma vez que os mesmos são rejeitados no ambiente sem o devido tratamento. $\mathrm{O}$ descarte adequado dos resíduos gerados nos estabelecimentos industriais, comerciais ou domiciliares, com base na legislação vigente, permite administrar melhor as relações entre essas atividades e o meio ambiente, constituindo uma responsabilidade compartilhada dos geradores desses materiais.

A ausência de gerenciamento dos resíduos sólidos traz consequências graves ao meio ambiente bem como às pessoas, tais como: a poluição do ar, a poluição visual, a poluição do solo, dos cursos de água (rios, riachos, lençóis freáticos etc.), além da proliferação de macro e micro vetores de doenças. Todos esses fatores provocam impactos diretos à população já que a mesma depende da qualidade e do equilíbrio dos recursos naturais para sobreviver.

Diante do consumo exacerbado de produtos industrializados, bem como da falta de sensibilização da sociedade acerca dos problemas gerados pela má disposição dos resíduos sólidos, a implantação da gestão integrada desses materiais torna-se indispensável, principalmente por objetivar soluções sustentáveis para os problemas ocasionados pelos mesmos (CAVALCANTE et al., 2012).

Neste sentido, o Direito Ambiental, que, segundo Barbosa (2007), configura-se por um complexo de normas e princípios com a finalidade de preservar o meio ambiente em suas diferentes formas, ou seja, natural, cultural, construído ou artificial e do trabalho, tem atuado de forma significativa no âmbito da gestão dos resíduos sólidos. A edição da lei 12.305/10, a qual instituiu a Política Nacional de Resíduos Sólidos- PNRS, é um exemplo desse avanço legislativo, uma vez que pela primeira vez na história da legislação ambiental brasileira os resíduos sólidos ganharam normatização própria. Nesse contexto, os estados membros também tiveram que incluir na sua legislação normas de cunho ambiental, legislando entre outros assuntos, acerca dos resíduos sólidos.

Tendo em vista que a geração de resíduos sólidos merece grande atenção no cenário jurídico brasileiro, a elaboração deste trabalho teve como base os seguintes questionamentos: A legislação aplicada à problemática dos resíduos sólidos em âmbito nacional refletiu no corpo legislativo paraibano? A legislação ambiental paraibana tem avançado no sentido de solucionar ou amenizar os problemas causados pela falta de gestão dos resíduos sólidos?

A pesquisa tem como objetivo analisar quais os principais aspectos e inovações trazidos pela Lei 12.305/10 (Política Nacional de Resíduos Sólidos), bem como seus reflexos nos dispositivos legais paraibanos.

\section{METODOLOGIA}

O presente trabalho consiste em uma pesquisa documental de dados secundários. Segundo Santos (2000), a pesquisa documental é realizada a partir de documentos contemporâneos ou retrospectivos, mas considerados cientificamente autênticos. Envolveu a análise da Lei 12.305/10, a qual instituiu a Política Nacional de Resíduos Sólidos, além de normas que tratam da problemática dos resíduos sólidos na Paraíba. As variáveis estudadas foram: principais contribuições e inovações da legislação para minimizar os impactos negativos decorrentes da falta de gestão dos resíduos sólidos no Estado da Paraíba. Os dados foram analisados tomando por base os princípios da pesquisa qualitativa. 


\section{RESULTADOS E DISCUSSÃO}

Por ser uma ciência que protege os bens jurídicos mais valiosos dos indivíduos tais como a vida, a liberdade, a dignidade da pessoa humana e o meio ambiente, o Direito precisa andar lado a lado com a evolução dos fenômenos sociais. Desta forma, verifica-se a necessidade constante de adequar o ordenamento jurídico, de modo que este atenda a geração de direitos surgidos a partir da perspectiva ecológica no mundo globalizado (CERICATO, 2008).

No que tange à problemática dos resíduos sólidos, destaca-se a Lei 12.305/10, a qual instituiu a Política Nacional de Resíduos Sólidos. Esta lei tramitou por duas décadas no Congresso Nacional, sendo resultado de ampla discussão entre governo, instituições privadas, organizações não governamentais, e sociedade civil, reunindo princípios, objetivos, instrumentos e diretrizes para gestão dos resíduos sólidos no país (RAUBER, 2011).

Vale mencionar que a Política Nacional de Resíduos Sólidos deve ser aplicada de forma integrada às demais normas ambientais brasileiras, tais como a Lei 6.938/81(Política Nacional de Meio Ambiente); Lei 11.445/07 (Política Nacional de Saneamento Básico); Lei 9.795/99 (Política Nacional de Educação Ambiental); Lei 10.257/01 (Estatuto das Cidades). Além disso, a partir dela todos os estados membros devem se articular no sentido de promover a gestão dos resíduos sólidos gerados em seus territórios. Por ser um dos instrumentos da gestão ambiental, a legislação nacional e estadual, deve determinar medidas que propiciem o melhor gerenciamento dos resíduos.

A PNRS estabelece a responsabilidade compartilhada, a qual corresponde ao conjunto de atribuições individualizadas e encadeadas dos fabricantes, importadores, distribuidores, comerciantes, dos consumidores e dos titulares dos serviços públicos de limpeza urbana e de manejo dos resíduos sólidos para minimizar o volume de resíduos sólidos e rejeitos gerados, bem como para reduzir os impactos causados à saúde humana e à qualidade ambiental decorrentes do ciclo de vida dos produtos (BRASIL, 2010). Desta forma, o Estado deve planejar, o setor produtivo deve reduzir os impactos ambientais na produção e ainda recolher seus produtos após o uso, e os consumidores devem buscar diminuir o consumo e separar o lixo para a coleta seletiva (PEREIRA, 2011).

Observando os princípios da responsabilidade compartilhada, foram publicadas no estado da Paraíba as Leis 9635/11 e 9505/11. A primeira torna obrigatória a utilização de depósitos de lixo pelos vendedores ambulantes de gêneros alimentícios de qualquer natureza para acondicionar os resíduos decorrentes da sua atividade (PARAÍBA,2011). A segunda dispõe sobre o uso de sacolas plásticas biodegradáveis para acondicionamento de produtos e mercadorias utilizadas nos estabelecimentos comerciais em todo o território da Paraíba (PARAÍBA, 2011). Também pode ser mencionada a Lei 10187/13, a qual determina que as empresas produtoras, distribuidoras de garrafas pet, ou plástico em geral estabelecidas no estado da Paraíba ficam obrigadas a criar e manter programas de reciclagem, reutilização ou reaproveitamento desses produtos, dando-lhes destinação final adequada a fim de evitar danos ao meio ambiente (PARAIBA,2013).

As normas supramencionadas demonstram a preocupação do legislador em adotar medidas que minimizem os impactos causados pelo descarte inadequado dos resíduos sólidos urbanos. Também chamam a atenção para a responsabilidade conjunta dos resíduos gerados diariamente no âmbito residencial ou comercial, cabendo a cada fonte geradora dar destinação adequada aos resíduos sólidos produzidos.

Outra inovação da Lei 12.305/2010 consiste nos planos de gestão que todas as unidades da federação e ainda o setor produtivo estão obrigados a realizar no sentido de promover o manejo dos resíduos sólidos. Compete à União a elaboração do Plano Nacional de Resíduos Sólidos. Já os estados membros devem elaborar seus planos estaduais devendo priorizar a constituição de microrregiões para trabalharem de forma integrada na gestão de seus resíduos. Contudo, é para os municípios que a lei traz o maior número de deveres, pois são detentores de competência constitucional para realização de serviços locais, dentre eles o de limpeza urbana (PEREIRA, 2011).

Desta forma, todos os Estados, municípios e indústrias devem criar planos para a gestão dos resíduos sólidos consubstanciados na implementação da coleta seletiva, construção de aterros sanitários, realização da logística reversa, promoção da Educação Ambiental. Em outras palavras, deve-se elaborar um conjunto de ações interligadas que propiciem, de forma adequada, o processo de coleta, transporte e destinação final dos resíduos gerados por cada ente. 
Segundo a PNRS, em agosto de 2014 encerra o prazo para que todos os municípios brasileiros substituam os lixões por aterros sanitários. Contudo, no estado da Paraíba os gestores não conseguiram sequer implementar os planos de gestão integrada de resíduos sólidos, os quais deveriam estar em execução desde 2012. Segundo dados do MPE (Ministério Público Estadual), 204 cidades paraibanas ainda não elaboraram os planos de gestão integrada de resíduos sólidos. Entre estas, pode-se citar as cidades de João Pessoa e Campina Grande, os dois maiores municípios do Estado. O MPE estima que apenas 40 municípios consigam elaborar os planos até agosto do corrente ano. Tal fato demonstra que as questões ambientais não são prioridade para administração pública. (MINISTÉRIO PÚBLICO DA PARAÍBA, 2014).

A lei 12305/10 também menciona mecanismos de inserção de organização de catadores de materiais recicláveis nos sistemas municipais de coleta seletiva, assim como possibilita o fortalecimento das redes de organizações desses profissionais e a criação de centrais de estocagem e comercialização regional. A valorização profissional do catador de material reciclável é um dos pontos mais relevantes da PNRS, pois demonstra o reconhecimento desses profissionais como agentes fundamentais da gestão ambiental.

A importância da atividade desenvolvida pelos catadores de matérias recicláveis pode ser externada pelos seguintes dados: em 2010, 47\% das embalagens de vidro e $70 \%$ do papel ondulado (papelão) consumido no país foi reciclado (CEMPRE, 2010). No tocante às latas de alumínio, 98\% da produção nacional de latas consumidas foram recicladas. Na reciclagem de latas de alumínio para bebidas, em 2010 o país reciclou 239,1 mil toneladas de sucata, o que corresponde a 17,7 bilhões de unidades, movimentando cerca de 1,8 bilhão na economia nacional (CEMPRE 2010). Todo esse material teve a destinação correta evitando danos ambientais, sociais, econômicos e de saúde pública.

No tocante aos catadores de materiais recicláveis, a Assembleia Legislativa da Paraíba, promulgou em 22 de dezembro de 2010 a Lei 9293, a qual Institui o Programa de Beneficiamento de Associações e Cooperativas de Catadores de Materiais Recicláveis da Paraíba, com a separação dos resíduos recicláveis descartados pelos órgãos e entidades da Administração Pública Estadual, direta e indireta, na fonte geradora, e a sua destinação aos catadores de materiais recicláveis organizados em cooperativas e associações (PARAIBA,2011). Normas como essa incentivam as pessoas que sobrevivem da catação de resíduos sólidos a se organizarem, melhorando as condições de trabalho desses profissionais. Contudo, a eficácia da lei depende da sensibilização dos gestores públicos para que coloquem a legislação em prática, bem como de toda a sociedade, para que esta se reconheça como agente da gestão ambiental.

Vale salientar que a Lei 12.305/10 menciona a Educação Ambiental como um dos seus instrumentos por ser fator determinante ao tratamento adequado e sustentável dos resíduos sólidos, pois é por meio dela que o processo de mobilização social acontece, alertando a população sobre importância de manter hábitos voltados para a sustentabilidade, além de torná-la corresponsável e coparticipante no processo de gestão dos resíduos sólidos.

A Lei 9795/99, a qual instituiu a Política Nacional de Educação Ambiental, é outro preceito jurídico que merece destaque dentro do corpo legislativo ambiental brasileiro. De acordo com o artigo 1ำ, entende-se por Educação Ambiental os processos por meio dos quais o indivíduo e a coletividade constroem valores sociais, conhecimentos, habilidades, atitudes e competências voltadas para a conservação do meio ambiente, bem de uso comum do povo, essencial à sadia qualidade de vida e sua sustentabilidade (BRASIL, 1999).

No corpo legislativo paraibano é possível encontrar algumas normas que relacionam a educação ambiental com o gerenciamento dos resíduos sólidos, entre estas pode-se citar a Lei 9766/12, a qual torna obrigatória a separação dos resíduos recicláveis do orgânico nas escolas públicas do Estado da Paraíba. Segundo a norma, a separação deve ser feita pelas instituições de ensino de forma a incentivar a prática pelos estudantes, agindo de forma instrutiva e socialmente comprometida (PARAÍBA, 2012). Neste caso, a educação ambiental está sendo trabalhada na modalidade formal, ou seja, direcionada à comunidade escolar.

No mesmo contexto, pode-se mencionar a lei 9574/11, que obriga as empresas permissionárias e/ou concessionárias do transporte intermunicipal a instalar recipientes coletores de lixo no interior dos coletivos, acompanhados de mensagens educativas para conscientização sobre a preservação ambiental, além de oferecer outras providências (PARAÍBA, 2011). Esta norma externa a educação ambiental trabalhada informalmente, isto é, direcionada a toda coletividade. 
A Educação Ambiental desempenha um papel fundamental no âmbito da gestão dos resíduos sólidos. Por meio dela é possível mudar a percepção da sociedade em relação ao meio em que vive, transformando antigos hábitos em condutas ambientalmente corretas e socialmente viáveis, pois constrói seres humanos mais críticos, capazes de lutar por melhores condições de vida. Mendonça et al. (2010) externam que a Educação Ambiental pode ser indicada como um dos possíveis instrumentos interdisciplinar capaz de capacitar e, ao mesmo tempo, sensibilizar a população em geral acerca dos problemas ambientais, nos quais se deparam a humanidade atualmente.

Ante a exposição de alguns dos pontos mais relevantes da Lei 12.305/10, e seus reflexos nas normas estaduais paraibanas, não resta dúvida de que a legislação ambiental brasileira quando devidamente aplicada, corresponde a um forte instrumento da gestão ambiental, a qual tem como objetivo a concretização do desenvolvimento sustentável. No entanto, para a execução de qualquer texto legal é preciso vontade política e social. Portanto, é necessário pensar em áreas viáveis à construção de aterros sanitários, acabar de uma vez com os lixões, implementar a coleta seletiva, praticar o consumo consciente, valorizar os catadores de matérias recicláveis e educar filhos e vizinhos para a mudança que está por vir (PEREIRA, 2011).

\section{CONCLUSÕES}

Ante o exposto, verifica-se que a publicação da Lei 12.305/12 (Política Nacional de Resíduos Sólidos) propõe uma nova forma de gerir os resíduos sólidos. Mecanismos como os planos de gestão, coleta seletiva, responsabilidade compartilhada, bem como a inclusão social e profissional dos catadores de matérias recicláveis tornam esta lei bastante inovadora, pois nunca no contexto legislativo brasileiro se deu tamanha importância à problemática dos resíduos sólidos.

Por ser uma norma federal, a PNRS deve ser seguida por todos os entes da federação, desta forma seus preceitos carecem de inserção na legislação estadual e municipal. No Estado da Paraíba, os princípios da lei 12.305/10 foram implementados no corpo legislativo por meio de algumas normas que tentam amenizar os problemas gerados pela má gestão dos resíduos sólidos. Contudo, as leis existentes estão longe de resolver todos os problemas relacionados aos resíduos sólidos. O não cumprimento dos prazos previstos na PNRS para a elaboração dos planos estaduais e para a extinção dos lixões externa a falta de prioridade das questões ambientais pelo poder público, bem como a falta de aparato técnico especializado que externe soluções viáveis para cada localidade.

É inegável que a lei 12.305/10 refletiu no âmbito legislativo paraibano, mas essa repercussão não gerou efeitos concretos na prática. Isso ocorre em virtude da falta se sensibilização prévia da comunidade, do Poder Público e setor privado, pois todos têm de compreender que são responsáveis pelos resíduos que geram, uma vez que a materialização do Direito não depende apenas da edição dos textos normativos, mas também da participação popular e da vontade política, requerendo, por conseguinte, o conhecimento e o empoderamento deste direito.

\section{REFERÊNCIAS}

BARBOSA, E. M. Introdução ao Direito Ambiental. Campina Grande - PB: EDUFCG, 2007.

BRASIL. Estatuto das Cidades, Lei 10.257. Diário Oficial da República Federativa do Brasil, Brasília, DF, 10 jul. 2001. Disponível em: <http://www.planalto.gov.br/ccivil_03/leis/LEIS_2001/L10257.htm>Acesso em: 23 mar. 2014.

Lei 9293 de 22 de dezembro de 2010. Assembleia Legislativa. Disponível em: http://alpb1.pb.gov. br:8082/sapl/sapl_documentos/norma_juridica/11077_texto_integral Acesso em: 26 de mar. de 2014.

, Lei 9505 de 14 de novembro de 2011. Assembleia Legislativa. Disponível em: http://alpb1.pb.gov. br:8082/sapl/sap1_documentos/norma_juridica/10121_texto_integral.Acesso em: 26 de mar. 2014. 
Lei 9574 de 07 de dezembro de 2011. Assembleia Legislativa. Disponível em: http://alpb1.pb.gov. br:8082/sapl/sap1_documentos/norma_juridica/10892_texto_integra. Acesso em: 26 d3 mar. 2014.

Lei 9766 de 22 de junho de 2012. Assembleia Legislativa. Disponível em: http://alpb1.pb.gov. br:8082/sapl/sap1_documentos/norma_juridica/10415_texto_integral. Acesso em 26 de mar. 2014.

, Lei 10.187 de 25 de novembro de 2013. Assembleia legislativa. Disponível em: http://alpb1.pb.gov. br:8082/sapl/sap1_documentos/norma_juridica/11327_texto_integral. Acesso em: 26 de mar. De 2014.

Política Nacional de Educação Ambiental, Lei 9795. Diário Oficial da República Federativa do Brasil, Brasília, DF, 27 abr. 1999. Disponível em: <www.planalto.gov.br/ccivil_03/Leis/L9795.htm>Acesso em: 15 mar. 2014.

Política Nacional de Resíduos Sólidos, Lei 12.305.Diário Oficial da República Federativa do Brasil, Brasília, DF,2ago.2010. Disponível em: <www.planalto.gov.br/ccivil_03/_ato2007-2010/.../lei/112305.htm>Acesso em:22 mar. 2014.

Política Nacional de Saneamento Básico, Lei 11.445. Diário Oficial da República Federativa do Brasil, Brasília, DF, 05 jan. 2007. Disponível em: <http://www.planalto.gov.br/ccivil_03/_ato2007-2010/2007/lei/ 111445.htm> Acesso em 17 mar.2014.

Política Nacional do Meio Ambiente, Lei 6.938. Diário Oficial da República Federativa do Brasil, Brasília, DF, 31 Ago. 1981. Disponível em:<http://www.planalto.gov.br/ccivil_03/leis/L6938.htm> Acesso em 15 mar. 2014.CAVALCANTE, L. P. S; MAIA, H. J. L; NASCIMENTO, J. M.; SOUZA, M. A.; SILVA, M. M. P. Percepção ambiental dos catadores de materiais recicláveis associados à ARENSA e dos informais que atuam no bairro do Tambor, Campina Grande - PB. Anais. III Congresso Brasileiro de Gestão Ambiental. Goiânia - GO, 19 a 22 mar. de 2014.

CEMPRE- Compromisso Empresarial para Reciclagem. Disponível em: http://www.cempre.org.br/ft_papel_ ondulado.php. Acesso em: 10 mar. 2014.

CERICATO, E. W.Direito Ambiental como meio de construção da cidadania. OAB - Ordem dos Advogados do Brasil, Florianópolis, 01 fev. 2008. Disponível em: <http://tmp.oab-sc.org.br/oab_site/upload/edna22306. pdf> Acesso em: 20 mar.2014.

MENDOZA, H. V.; RODRIGUEZ, E. A.; VASCONCELOS, E. M.; MOYA, A. F. C. Situación de la separación de residuos sólidos urbanos en Santiago, Nuevo León, México. Ciencia Uanl. v. XIII, n. 3, julio-septiembre 2010. Disponível em: <http://redalyc.uaemex.mx/src/inicio/ArtPdfRed.jsp?iCve=40215495007> Acesso em: 22 mar. 2014.

PARAÍBA, Lei 6935 de 22 de dezembro de 2011. Assembleia Legislativa. Disponível em: http://alpb1.pb.gov. br:8082/sapl/sapl_documentos/norma_juridica/6713_texto_integral.Acesso em: 26 de mar de 2014.

PEREIRA, T. C. G. Política Nacional de Resíduos Sólidos: Nova regulamentação para um velho problema. Direito e Justiça. v.11. n.17, 2011. Disponível em: http://srvapp2s.urisan.tche.br/seer/index.php/direito_e_justica/article/view/719. Acesso em: 24 mar. 2014.

RAUBER, M. E. 2011. Apontamentos sobre a Política Nacional de Resíduos Sólidos, instituída pela Lei Federal 12.305, de 02/08/2010. Revista Eletrônica Gestão, Educação e Tecnologia Ambiental. v.4. n.4, Disponível em: <http://cascavel.ufsm.br/revistas/ojs2.2.2/index.php/reget/article/view/3893/2266> Acesso: 24 mar. 2014.

SANTOS, A. R. dos. Metodologia Científica: a construção do conhecimento. 3. ed. Rio de Janeiro: DP\&A, 2000. 